Check for updates

Cite this: J. Anal. At. Spectrom., 2018, 33, 992

Received 24th November 2017 Accepted 18th April 2018

DOI: $10.1039 / \mathrm{c} 7 \mathrm{ja00386b}$

rsc.li/jaas

\section{New applications of spectroscopy techniques reveal phylogenetically significant soft tissue residue in Paleozoic conodonts $\uparrow$}

\author{
D. F. Terrill, (DD ${ }^{\star a}$ C. M. Henderson (iD ${ }^{a}$ and J. S. Anderson (DD ${ }^{b}$
}

Mineralized tissues such as bones and teeth form the vast majority of what is known of the vertebrate fossil record, whereas non-mineralized tissues are primarily known only from exceptional localities. New chemical techniques have been developed or applied over the last two decades to analyze potential biomarkers for evidence of soft tissues such as keratin, including immunohistochemistry and synchrotron-based chemical analyses among others. These techniques have led to the identification of keratin in fossil feathers and claws by the presence of biologic sulfur residues. Histological sections of Permian and Ordovician aged conodont dental elements are examined for the presence and distribution of soft tissue biomarkers utilizing a suite of spectrometry techniques. Data obtained using energy dispersive X-ray spectrometry consistently show elemental sulfur distributed within the earliest growth stages of the conodont crown as well as in the connected basal body, while X-ray photoelectron spectroscopy analysis supports an organically endogenous origin for at least some of this sulfur. These data suggest that conodont elements, at least in early growth stages, were partly composed of soft tissue, possibly keratin, and were not purely phosphatic. Soft tissue data such as these can have a dramatic effect on our understanding of the early vertebrate fossil record. Incorporating these new data into a phylogenetic analysis suggests conodonts are stem cyclostomes, which is contrary to their current identification as stem gnathostomes.

\section{Introduction}

One of the greatest challenges in interpreting the fossil record is overcoming the lack of soft tissue preservation. Whereas much can be learned from studying mineralized tissues such as bones and teeth, a great deal of biological information is lost due to the decay of soft tissues. As a result, when soft tissues are preserved, our understanding of fossil groups can dramatically improve. Nowhere has this been more evident than in the study of Mesozoic dinosaur fossils, whose evolutionary relationship to modern birds was solidified by the discovery of feathered nonavian dinosaur remains. ${ }^{1}$ Soft tissue discoveries are not restricted to dinosaurs however, with chordate and vertebrate remains having been discovered in localities with exceptional biotic preservation, such as in the Burgess Shale. ${ }^{2-4}$ Some of these finds have provided critical information on the evolution of the earliest vertebrates, from animals such as Pikaia and Metaspriggina in the Burgess Shale Formation in Canada, ${ }^{5,6}$ to

${ }^{a}$ University of Calgary, Department of Geoscience, Canada. E-mail: dfterril@ucalgary. $\mathrm{ca}$

${ }^{b}$ University of Calgary, Department of Comparative Biology and Experimental Medicine, Canada

$\dagger$ Electronic supplementary information (ESI) available. See DOI: 10.1039/c7ja00386b conodont animals from the Granton Shrimp beds of Scotland, ${ }^{7}$ even with some anatomical decay.

Conodonts are an enigmatic group of fossils due to the rarity of body fossils. Originally discovered in $1856,{ }^{8}$ the fossil record for conodonts is almost completely composed of small phosphatic elements that resemble teeth (Fig. 1). The name conodont was used for a long time to describe these elements directly. The body of the animal was not known until the 1980s, when a small eel-like animal was recognized from the Granton Shrimp Beds near Edinburgh, complete with an apparatus comprising several phosphatic conodont elements. ${ }^{7}$ Conodont nomenclature can be difficult to broach, so for the purposes of this study we will refer to the animal itself as a conodont, while the tooth-like elements will be referred to as either conodont elements, conodont dental elements, or conodont dentition.

The biological affinity of conodonts has been a topic of long debate. As conodonts first appear during the Cambrian Period, ${ }^{9,10}$ they potentially represent a significant step in the evolution of vertebrates. Conodont elements compositionally resemble vertebrate enamel, while histological studies show evidence of occlusion and wear, ${ }^{11-13}$ leading some to conclude that conodont elements are in fact homologous (linked through evolution) with vertebrate teeth. ${ }^{\mathbf{1 3 , 1 4}}$ Perhaps the strongest evidence of the vertebrate affinity of conodonts comes from the soft body discovery of the body fossil in the 1980s, ${ }^{7}$ with 

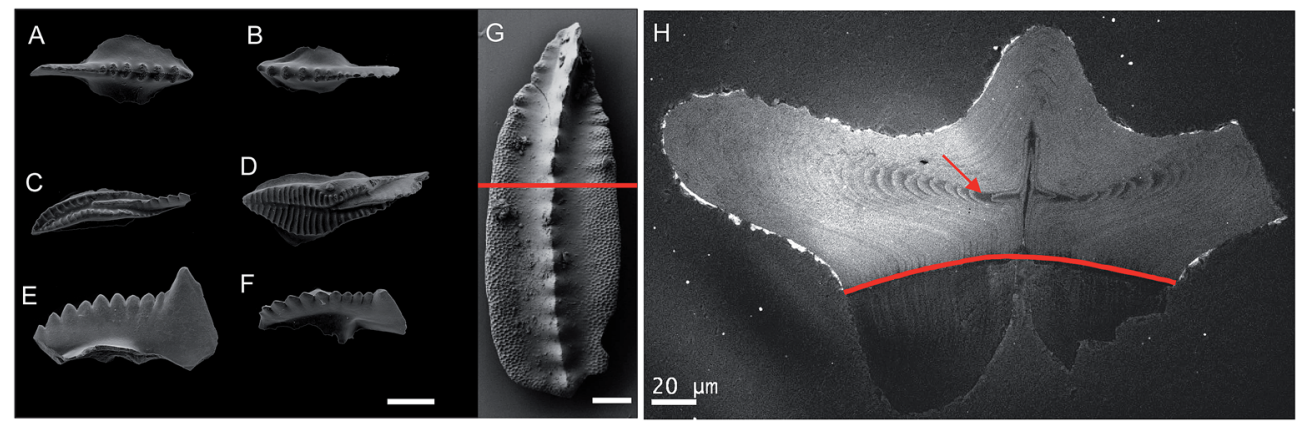

Fig. 1 Examples of conodont fossils and brief anatomical description. SEM images on the left (A-F) are unpublished images of conodont elements collected from the Tensleep Formation. They represent three different genera, including Sweetognathus (A, B), Streptognathodus (C, D), and Hindeodus (E, F). The scale bar below fossil F represents 200 microns, and is consistent across (A-F). Image (G) shows an example of Jinogondolella, one of the conodont genera examined in this study. Sections through conodont elements for this study were made parallel to the red line. Scale bar represents 100 microns. Image $(\mathrm{H})$ is a cathodoluminescence image of a Jinogondolella conodont from this study. The view seen here is obtained by cutting across the narrow axis of the fossil. The red line is highlighting the divide between the two major structures of the conodont element, the crown above (analogous to the part of the tooth exposed above the gum in mammals) and the basal body below (analogous to the root). The red arrow is highlighting tissue that is compositionally different from the surrounding tissue, which is identified in this paper as intralamellar tissue, with the surrounding tissue being known as lamellar tissue.

subsequent body fossil studies further supporting this conclusion. ${ }^{15-17}$ Through careful character and phylogenetic analysis some studies have concluded that conodonts are stem gnathostomes (jawed fishes), ${ }^{5,18,19}$ though there remain difficulties with this assignment in part due to the unusual method of growth observed in their dentition. The oral elements of conodonts are seen to grow via external apposition of lamellae, with alternating periods of growth and function..$^{9,20}$ This differs from the vast majority of vertebrate teeth, which are fully formed when they erupt, and while some vertebrates such as lungfish are known to enlarge their tooth plates through lateral accretion of denticles, ${ }^{21}$ none of these groups completely envelop their existing teeth during this additional growth as conodonts must have. This has led to some skepticism surrounding the vertebrate affinity of conodonts, ${ }^{22,23}$ and whereas most studies agree that they are indeed vertebrates, ${ }^{7,15-17}$ recent work has concluded that conodont elements are the result of convergent evolution and are not homologous with other vertebrate teeth. ${ }^{10}$

Although both hard and soft tissues of conodonts have been recovered, a recent microprobe analysis has revealed previously unidentified chemical signatures within conodont elements. ${ }^{24}$ Of particular interest to this study is the presence of sulfur, as sulfur has recently been used as a biomarker indicator of the keratin protein in Mesozoic fossils..$^{25-29}$ The simple presence of sulfur is not sufficient to confirm keratin preservation however, with both the distribution and oxidation state of the sulfur being critical to interpret the origin of the observed sulfur. In this study, conodont elements from different localities and genera (see Methods section for details) were analyzed using an array of microscopy techniques including SEM, backscatter (BSE), cathodoluminescence (CL), and energy dispersive X-ray spectrometry (EDX). The distribution of sulfur and other key elements like carbon and iron and their association with different tissues within the conodont oral element have been mapped. X-ray photoelectron spectroscopy (XPS) on a conodont element was then used to determine the oxidation states present and thereby determine whether the sulfur could have a biological origin.

In addition to the above analysis, a lamprey oral element was examined using the same suite of techniques listed above, as lampreys and hagfish have at times been evolutionarily linked to conodonts. This is largely due to the similarities in morphology of the oral elements and body form. ${ }^{30}$ Mesozoic and Paleozoic lamprey specimens also reveal a much smaller animal than modern examples and are comparable in size to conodont body fossils. ${ }^{31,32}$ Data obtained in this study were included in a phylogenetic analysis to further examine evolutionary relationships between conodonts and other vertebrates.

\section{Materials and methods}

Conodont specimens used from this study include elements of Jinogondolella and Clarkina, which were obtained from the Bell Canyon Formation of West Texas and Ali Bashi Formation of Iran respectively. These elements were selected due to their pristine preservation and very low thermal maturity or colour alteration index (CAI). In addition, one element of Mesogondolella from the Canadian Arctic and one chirognathid conodont from the Harding Sandstone of Colorado were also examined. Finally, two oral elements from a sea lamprey were extracted and analyzed utilizing the same methods as the conodont elements as described below. All conodont specimens were obtained from the collection of Dr Charles Henderson at the University of Calgary, while the lamprey specimens were collected from the teaching labs of the Department of Biological Sciences at the University of Calgary.

Most data for this study were obtained using the FEI Quanta 250 FEG Field Emission Scanning Electron Microscope (FESEM) in the Instrumentation Facility for Analytical Electron Microscopy, Department of Geoscience, University of Calgary. The FE-SEM is equipped with a variety of instruments, including Bruker Quantax EDX system for X-ray analysis, and 
a Gatan MonoCL4 Elite for CL detection. Specimens needed to be mounted prior to observation with the FE-SEM, with orientation of the specimens being of utmost importance. In general, most specimens selected for analysis were broken along planes that were favourable for mounting. Specimens were then placed carefully into precut chambers covered with tape in order to maintain the preferred orientation (see ESI $\dagger$ ). After this placement, the chambers were then filled slowly with epoxy and left to dry. Once hardened, the disk was polished to create a smooth cross-sectional surface through each specimen, however a few scratches persisted. This differs from the preparation of most histological conodont specimens, which have relied heavily on thin sections and acid etching that may disturb preserved organic compounds. Finally, each mount was given a carbon coating at the final step before placement into the FE-SEM. Specimens were then analyzed utilizing the full suite of tools available including SEM, BSE, CL, and EDX.

XPS data were collected using a PHI Versa Probe 5000 spectrometer equipped with a hemispherical analyzer working under vacuum, which is located in the Catalyst Research Group in the Department of Engineering at the University of Calgary. Samples were prepared in an identical fashion to those analyzed with the FE-SEM. All of these data were acquired using monochromatic $\mathrm{Al} \mathrm{K} \alpha$ radiation (1486.7 eV, $150 \mathrm{~W}$ ), and the binding energies were corrected taking C $1 \mathrm{~s}(284.8 \mathrm{eV})$ as a reference.

Initial spectra were obtained from an energy range of 0-1400 eV with a $1 \mathrm{eV}$ resolution to identify all possible elements. Subsequent spectra were obtained under identical conditions, but limited the spectra range from 0-1200 eV. A pass energy of $187.85 \mathrm{eV}$ was used for all surveys. To analyze sulfur, the acquisition window was narrowed significantly to just $20 \mathrm{eV}$, with a pass energy of $23.5 \mathrm{eV}$. This provided the higher resolution needed to analyze oxidation states of sulfur.

The rapid change of the background observed on these spectra, resulting from energy loss processing occurring as the photoelectrons are ejected from the surface material, lead to a correction other than a simple linear interpolation of the intensities at either end of the energy interval. The most common procedures for determining backgrounds in XPS and their uses are summarized in the ISO Technical Report short communication by Kövér. ${ }^{33}$ In this study, a Shirley-Sherwood background subtraction was applied prior to curve fitting ${ }^{34}$ and Gaussian-Lorentzian decomposition parameters were also used. For the quantitative analysis, the instrumentation was calibrated according to the ISO 15472:2001. ${ }^{35}$ All spectra were acquired using the Smartsoft software, and were processed using the MULTIPACK software v. 9.5.0. The peak areas used to obtain the atomic composition were corrected using response factors based on Scofield's photoionization cross-sections $\sigma$ (ref. 36) according to Seah et al. ${ }^{37}$

Two Jinogondolella conodont elements and a lamprey element were analyzed using XPS. The spot size for the XPS beam is 100 microns, which exceeds the dimensions of an individual conodont element. As a result, an additional analysis was performed on the mounting epoxy to ensure that the detected sulfur signature was from the fossil specimens and not the mounting epoxy.

\section{Results}

\section{Scanning electron microscopy analysis of conodont dentition}

Of the techniques utilized in this study, standard SEM imaging revealed the fewest details of the internal structure of the conodont element, with features tending to be subtle or not observable. SEM images do however convey the topography of the sample, and have been included to show that each sample has been polished to a flat surface. This is important, as topography of a sample may affect observations using other methods.

In contrast to standard SEM, BSE imaging allows for discernment of some internal structures such as lamellar and intralamellar tissue (Fig. 2). While lamellar tissue composes the bulk of the crown, intralamellar tissue can be seen in pockets within the lamellar tissue, and has previously been identified as a hypocalcified portion of the lamellar tissue associated with the exaggerated lateral growth of the platform. ${ }^{38}$ Growth laminations within the entire crown are observed to be as small as

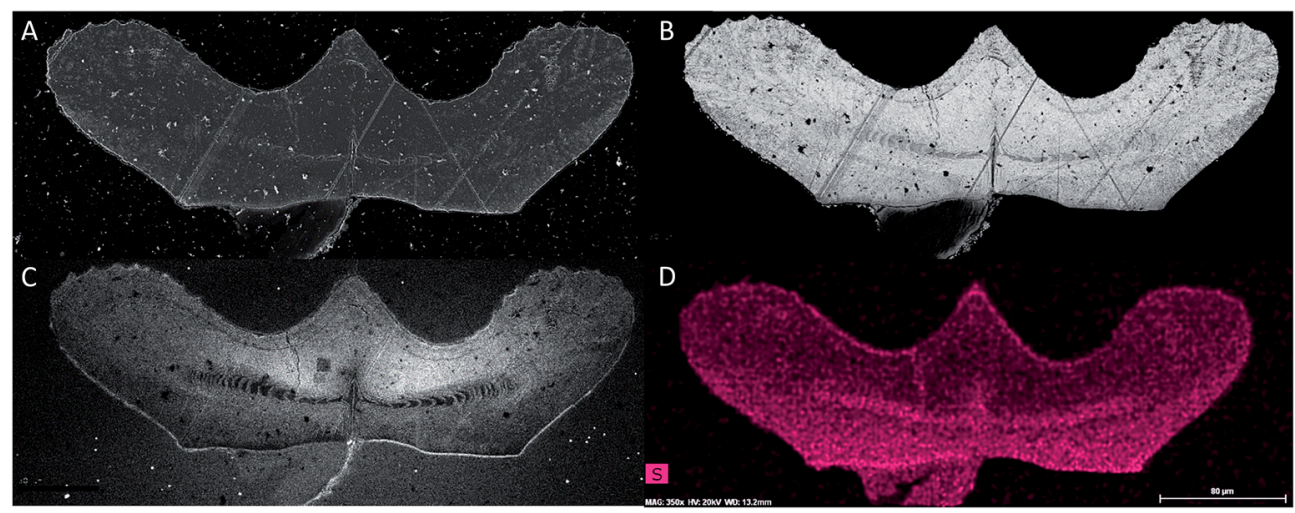

Fig. 2 Histological and histochemical data obtained from a specimen of Clarkina. A single section through a specimen of Clarkina as seen through secondary electron microscopy (A), backscatter electron microscopy (B), cathodoluminescence (C), and the energy dispersive X-ray spectrometry map of sulfur (D). While intralamellar tissue can be seen in backscatter images, it is most noticeable in cathodoluminescence images where it appears dark. This area strongly corresponds with higher sulfur concentrations as seen in EDX. The scale bar in the lower right corner represents 80 microns, and is consistent across all images. On average the element is approximately 360 by 100 microns in dimension. 
0.3 microns, an order of magnitude smaller than previously reported, ${ }^{39}$ while intralamellar tissue is observed only in the earliest growth stage of the conodont element, which is referred to as the protoelement. ${ }^{40}$

The intralamellar tissue becomes even more noticeable when observed using CL images (Fig. 2C), which clearly show the extent of the tissue within the crown. CL imaging can also provide some compositional information, as the wavelength of emitted photons from a sample is correlative to its composition. In this study however, filters that spanned a wide range of wavelengths were utilized. While this allows observation of structural variations within the fossils, these data do not allow for confident conclusions about the composition.

To these observations, data obtained using EDX spectrometry were added, focussing primarily on the distribution of sulfur as well as carbon and iron. Sulfur has previously been identified as a component of conodont elements once before, ${ }^{24}$ and that result is confirmed by the work presented in this study. Unlike the previous study, which concluded that sulfur concentrations within the crown increased in proportion to the distance from the oral surface, the higher resolution of this study shows that the highest concentrations of sulfur coincide with the presence of intralamellar tissue, which is concentrated within the innermost areas of the conodont crown (Fig. 2D). The distribution of carbon is of considerable interest due to its importance in organic tissues; limited amounts of carbon were primarily concentrated in tandem with sulfur in the intralamellar tissue (Fig. 3C). Iron, which can accumulate after burial as the mineral pyrite $\left(\mathrm{FeS}_{2}\right)$, was found to be absent (Fig. 3, 4).

Along the outer surface, the only elements to show noticeable concentration changes are sodium, chlorine, and to a lesser extent fluorine, which are all elevated along the oral surface of the element and not the base. This has previously been suggested to be the result of oral exposure to sea water during the life of the animal and not the result of post burial alteration. ${ }^{24}$

\section{XPS analysis}

The XPS results corroborate the presence of sulfur observed in the conodont elements by the EDX analysis. XPS analysis also allows us to determine whether the sulfur present in the sample had a biological (endogenous) or post-deposition inorganic (exogenous) origin. XPS analysis is capable of both quantifying the atomic percentage of each element present, as well as determining the bonding environment for individual elements. This allows for the determination of oxidation states of elements such as sulfur, which can be used to evaluate whether the element has a biologic or diagenetic origin. If biologic sulfur is present, XPS analysis should reveal one of two oxidation states: $\mathrm{S}^{2+}$ for disulfide bonding present in cysteine molecules; or $\mathrm{S}^{4+}$ that can be attributed to cysteic acid, a common by-product of chemical transformation of amino acids such as cysteine. ${ }^{\mathbf{4 1}}$ Cysteic acid has been identified in $\operatorname{modern}^{42}$ as well as fossil keratins ${ }^{28}$ using XPS and has been used to support the identification of fossil keratin in the Cretaceous bird, Rahonavis. ${ }^{28}$

The first analysis was performed on the mounting epoxy (Fig. 5). The epoxy is shown here to be composed mostly of carbon and oxygen, with smaller amounts of nitrogen and trace amounts of chlorine. No sulfur is detected, indicating that sulfur signals detected from the conodont samples are produced only from the fossil and not the epoxy.
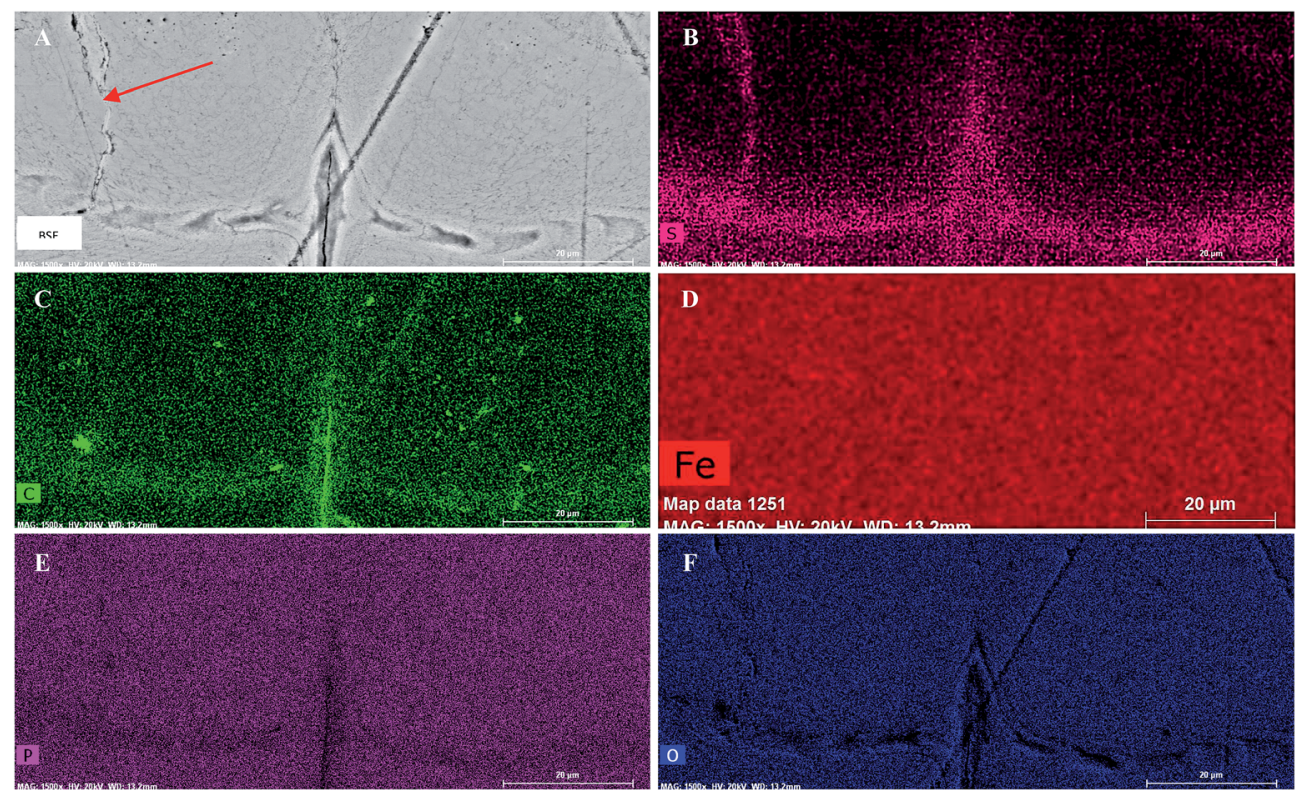

Fig. 3 BSE and EDX images of central growth region in Clarkina from Fig. 2. The distribution of important elements within the central growth region, or protoelement, is shown. The arrow in the BSE image (A) points to a small crack that may have occurred pre-burial. Other linear topographic features are scratch marks from the polish. Sulfur (B) and carbon (C) occur in elevated concentrations along the major growth axes, with sulfur also occurring in the pre-burial crack. Iron is absent (D), while phosphorous (E) and oxygen (F) both show decreases in concentration within the intralamellar tissue. 

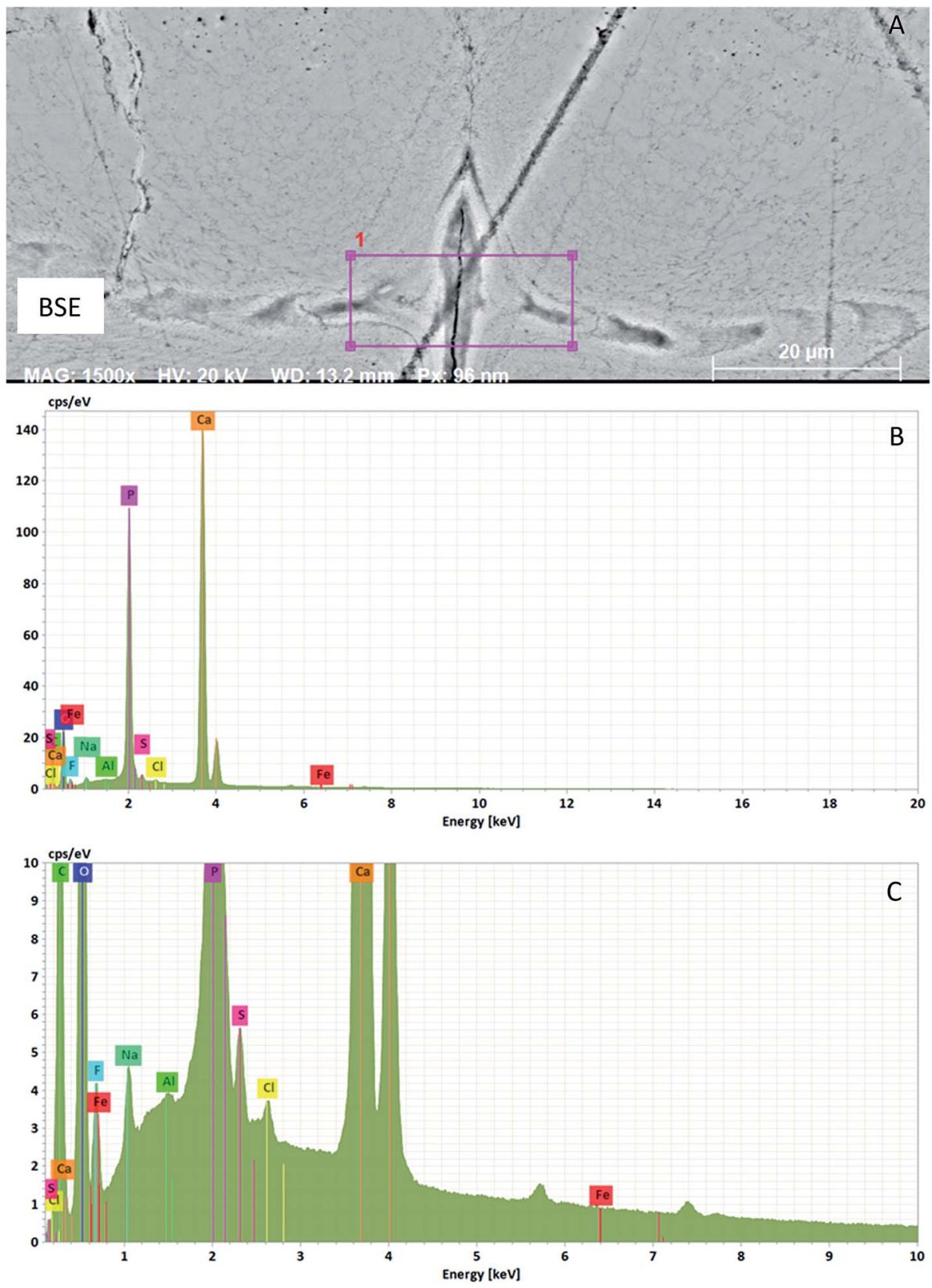

Fig. 4 Full EDX spectrum of Clarkina specimen seen in Fig. 2. A localized section of Clarkina was analyzed using EDX, as indicated by the box in (A). (B) and (C) are the same spectrum, but with different vertical scaling. Note the absence of iron in the sample.

The conodont elements of Jinogondolella show a composition rich in carbon and oxygen (Fig. 6), however most of the signal for these elements likely comes from the epoxy as the $\mathrm{X}$-ray beam spot size exceeds the dimensions of the fossil. Some of the oxygen is also bonded to calcium, carbon and phosphorous within the conodont elements, which is consistent with the dominant mineralogy of conodont elements (approximates apatite, $\left.\mathrm{Ca}_{5}\left(\mathrm{PO}_{4}, \mathrm{CO}_{3}\right)_{3}(\mathrm{~F})\right)$. We also see small amounts of sulfur and lead in this analysis.

A high-resolution spectrum of the $\mathrm{S} 2 \mathrm{p}$ signal was obtained from one Jinogondolella specimen to analyze the oxidation state of the preserved sulfur. The sulfur signal is produced by $\mathrm{S}^{4+}$ and
$\mathrm{S}^{6+}$ oxidation states as determined by peak fitting (described in the Methods and materials section). The total amount of detected sulfur represents about $0.1 \%$ of the total signal (Fig. 6), which is just above the detection limit of the instrumentation. In order to minimize the uncertainty when measuring the sulfur speciation, the high resolution spectrum was collected for 334 minutes (Fig. 7). We have determined the standard uncertainty due to counting statistics for the total $\mathrm{S}^{4+}$ signal is approximately $2.2 \%$. We estimate the systemic uncertainty of the background subtraction, calibration, and other factors to be $0.8 \%$. Of the sulfur signal presented here, $37.3 \pm 3 \%$ is in the $4+$ state. 


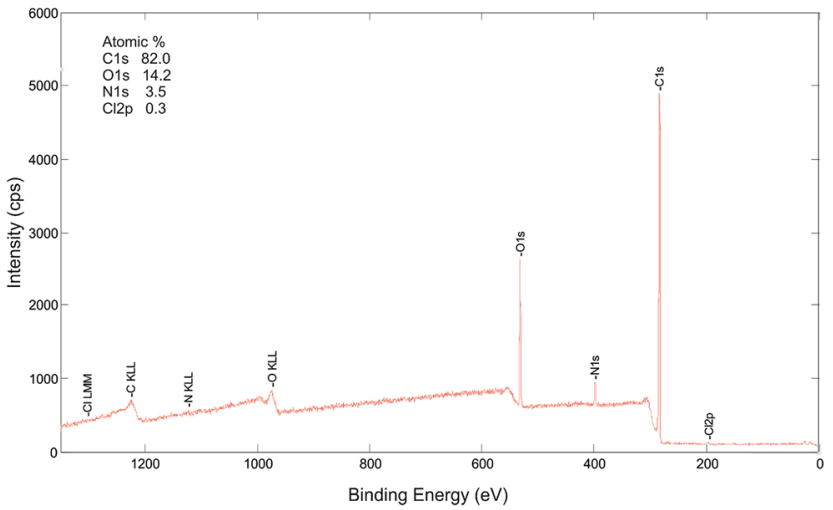

Fig. 5 XPS analysis of epoxy mounting polymer. This analysis was performed on the mounting epoxy to determine if sulfur was present. As sulfur is not detectable, it can be assumed that any sulfur signature detected from either the conodont element or the lamprey element is not the result of signal contamination from the epoxy. Spot size is 100 microns, and analysis was performed over 225 minutes.

\section{Lamprey analysis using EDX and XPS}

For comparison, a modern lamprey oral element was analyzed using all the same procedures as for the conodont analyses. Lamprey elements are well known to be composed of keratin, ${ }^{43}$ so it was expected to find higher concentrations of organic compounds and elements, including carbon and oxygen. One of the observed elements is sulfur, which XPS analysis estimated to represent a similar atomic percentage of the element as seen in conodont elements (Fig. 8). Trace amounts of calcium were observed in both XPS and EDX, with EDX images showing small concentrations of calcium and phosphorous near the internal surface of the lamprey element (Fig. 9).

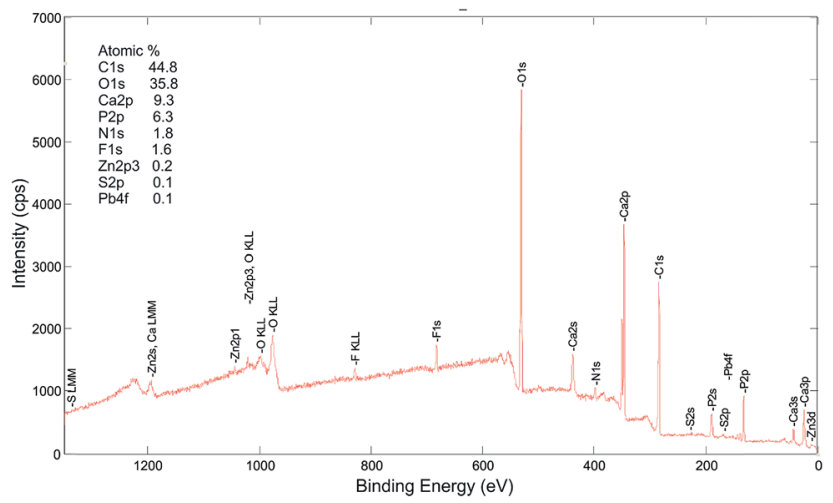

Fig. 6 XPS analysis of conodont (Jinogondolella) element. This analysis shows the bulk composition of a conodont element in atomic percentages. As the spot size is 100 microns, it is highly likely that a portion of this analysis was performed on the surrounding epoxy. This will result in elevated atomic percentages for elements that are located in the epoxy (mostly carbon and oxygen, as seen in Fig. 5), while decreasing atomic percentages for elements located in the fossil material (such as calcium, phosphorous, and even sulfur). Notably, sulfur is present in a similar percentage as seen in the lamprey element, especially when the effects on the analysis of picking up parts of the epoxy are considered. Spot size is 100 microns, and analysis was performed over 225 minutes.

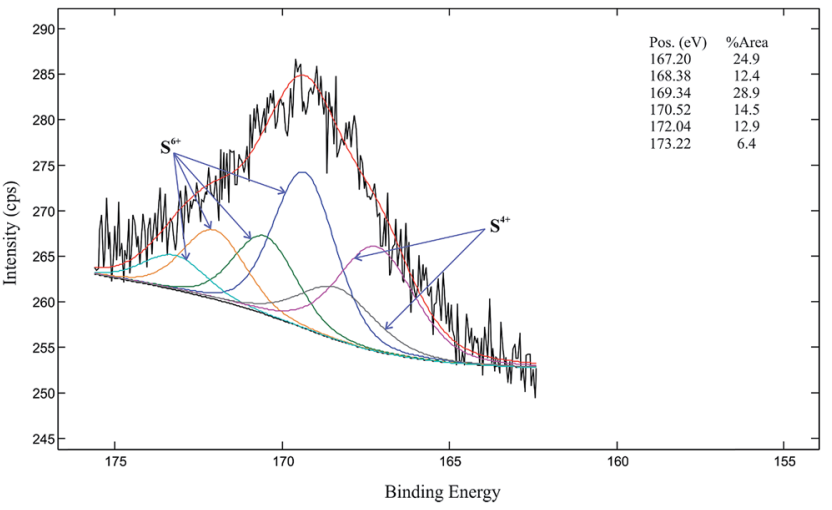

Fig. 7 High resolution XPS spectrum focussing on the sulfur $2 p$ energy peak. These data show contributions from multiple species of sulfur, and known sulfur peaks have been fitted to these data to calculate the relative abundances of each, with these abundances shown in the top right corner. As overall sulfur counts are low, the sulfur spectra was subject to significant uncertainty. The analysis was run for 334 minutes in order to minimize the uncertainty. Spot size is 100 microns.

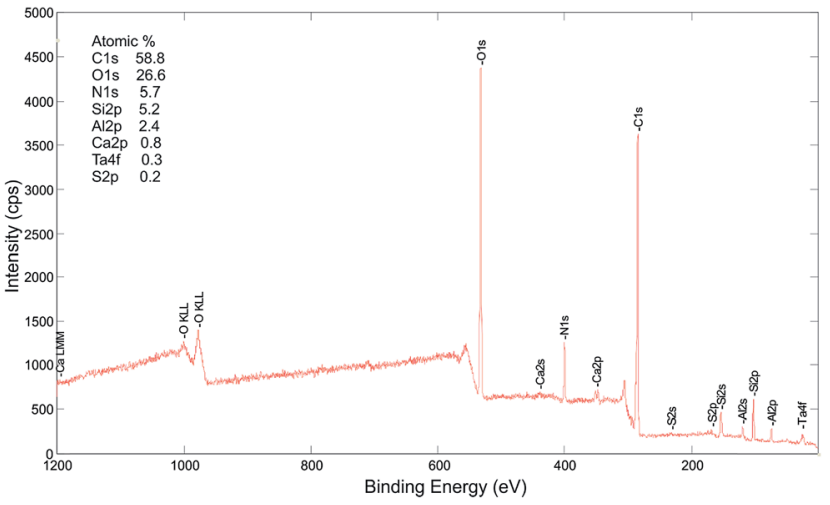

Fig. 8 XPS Analysis of a lamprey tooth element. Bulk atomic composition of the lamprey element. The lamprey element is much larger than conodont elements, so the bulk of the signal is believed to be from the sample and not the epoxy. Composition is dominated by carbon and oxygen. Sulfur is measured at about $0.2 \%$ of the total composition, while calcium is $0.8 \%$. Spot size is 100 microns, and analysis was performed over 160 minutes.

\section{Discussion}

\section{Conodont element analysis}

While sulfur has been previously identified in conodont elements ${ }^{\mathbf{2 4}}$ and is easily seen here in EDX imaging, a key question to address is whether this sulfur represents preserved soft tissue or is an artefact of diagenesis. To fully address this problem, many avenues of investigation were explored as detailed above. Specimens chosen for this study lacked any visual evidence of alteration, such as recrystallization. EDX data also do not show any chemical evidence of alteration, as the only chemical changes on the external surface (which is the most likely location for alteration to occur) are in elements such as sodium, that can be explained by the lifetime exposure to seawater in the mouth of the conodont. 


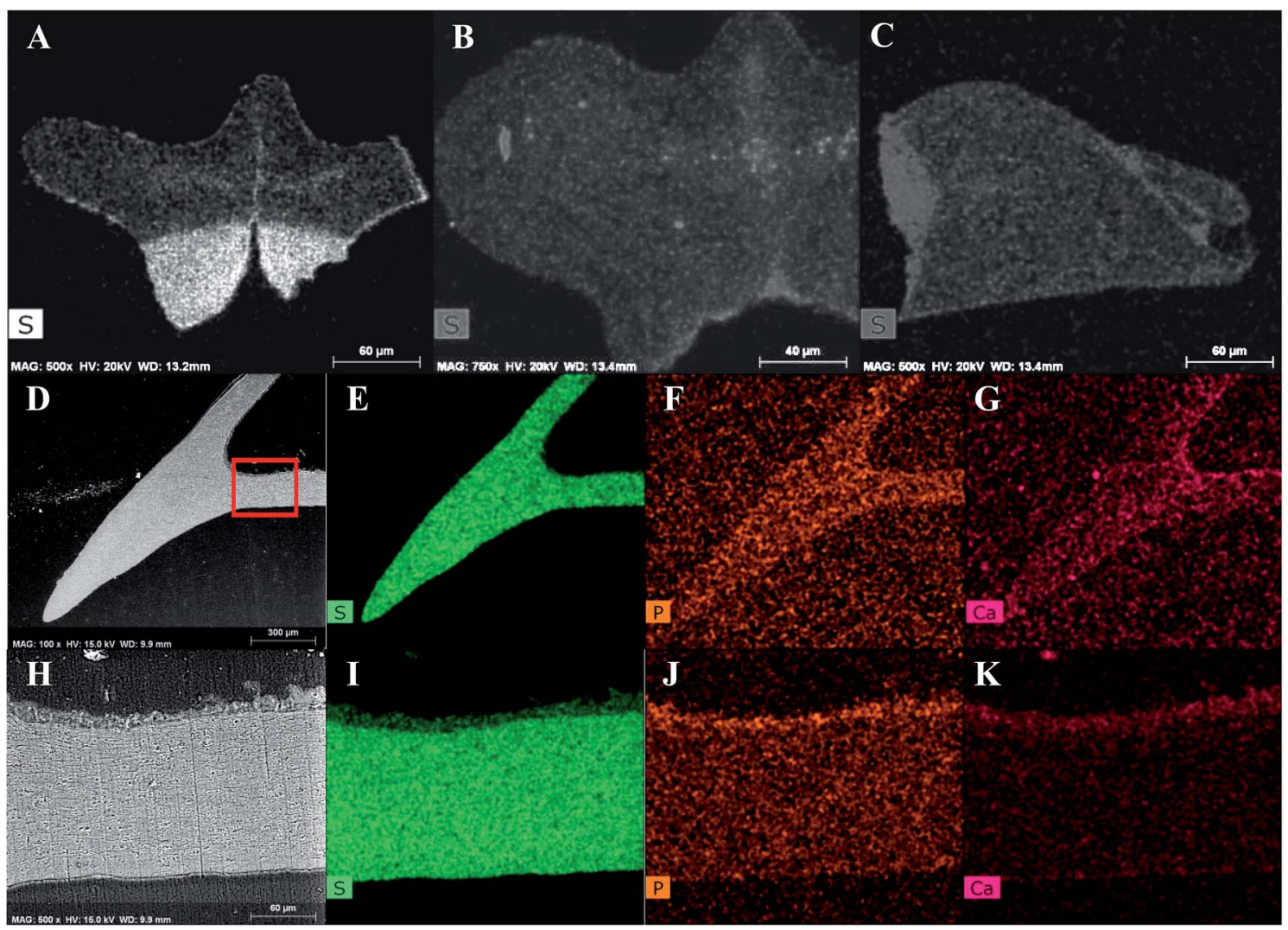

Fig. 9 Distribution of sulfur in conodont elements and sulfur, calcium and phosphorous in lamprey elements. Sulfur distribution in Jinogondolella from the Permian of Western Texas (A), Mesogondolella from the Permian of Northern Canada (B), Chirognathid conodont fragment from the Ordovician of Colorado (C). Brighter regions indicate higher concentrations of sulfur. (D-K) BSEM and EDX data from a lamprey element detailing sulfur (green), phosphorous (orange) and calcium (pink) distributions, with increased brightness being an indicator of increased concentrations. The red box in image (D) highlights the area seen in images (H-K). Scale bar in image (D) is 300 micrometres and applies to images $(D-G)$ while the scale bar in image $(H)$ represents 60 micrometres and applies to images $(H-K)$.

In addition to looking for surface alteration signatures, we also examined the possibility that sulfur had been emplaced after burial of the conodont elements without significantly altering the external surface. The most common inorganic mineral to be precipitated during burial is pyrite $\left(\mathrm{FeS}_{2}\right)$, which has a significant iron content. EDX data clearly show that iron is absent from all parts of the studied conodont elements, so pyrite was ruled out as a source of sulfur. It should be noted that some mottling is evident in EDX images, particularly in sulfur (Fig. 2D, and 3B) and carbon (Fig. 3C); this is likely due to a combination of different effects, including minor topographic effects in the intralamellar tissue, instrumentation effects such as detector noise, and biological effects such as life time contact with soft tissue. ${ }^{24}$

Another possibility to consider is that sulfur precipitated as inorganic sulphates. To determine this, XPS analysis was employed to measure oxidation states of the sulfur. The results clearly show the presence of $\mathrm{S}^{6+}$, which is consistent with sulphate, however $\mathrm{S}^{4+}$ was also detected, which would be consistent with sulfur derived from degraded keratin. It is worth noting that the basal body of conodont elements is generally less mineralized than the crown, and is therefore more porous; both parts of the conodont element collectively contribute to the signal. It is possible that sulfur in the basal body of the fossil is diagenetic in origin, while original biologic sulfur is found in the less porous conodont element crown. The methods used in this study have insufficient resolution to discern this difference, however it could be possible to make this determination using X-ray absorption near edge spectrometry (XANES).

The significance of the presence of biologic sulfur is twofold. First, given the consistent emplacement within the earliest growth stage of the element, sulfur concentrations are an indicator of the juvenile stage of conodont growth as well as a chemical marker for intralamellar tissue. Second, sulfur is not a common element in most amino acids, being present in only cysteine and methionine. Methionine plays a critical role in protein synthesis, but cysteine is notable for its role in protein structure due to the strength of disulfide bonds formed between cysteine molecules. ${ }^{44}$ This is most important in keratin, which derives its stiffness from these disulfide bonds. ${ }^{45}$ Stiffer keratins such as horns and claws have higher concentrations of cysteine and therefore of sulfur compared to softer keratins such as epidermis ${ }^{45}$ and other tissues. Biologic sulfur is therefore more likely to be preserved from degraded keratin tissue as opposed to other tissues such as collagen due to higher sulfur content. 
A

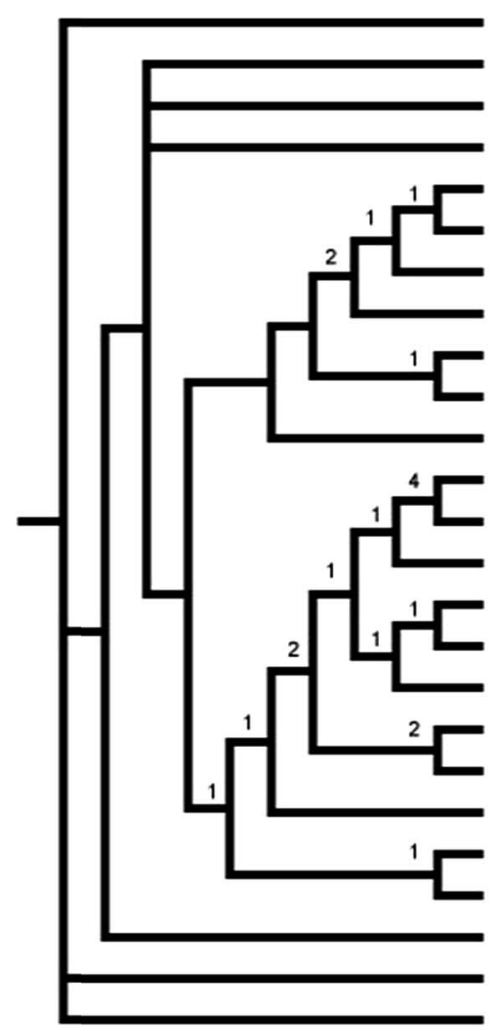

Hemichordata

Metaspriggina

Myllokunmingia

Haikouichthys

Petromyzontida

Mesomyzon

Priscomyzon

Mayomyzon

Mixinoidea

Myxinikela

Euconodonta

Gnathostomata

Osteostraci

Galeaspida

Arandaspida

Astraspis

Heterostraci

Loganellia

Turinia

Anaspida

Jamoytius

Euphanerops

Pikaia

Cephalochordata

Tunicata
B

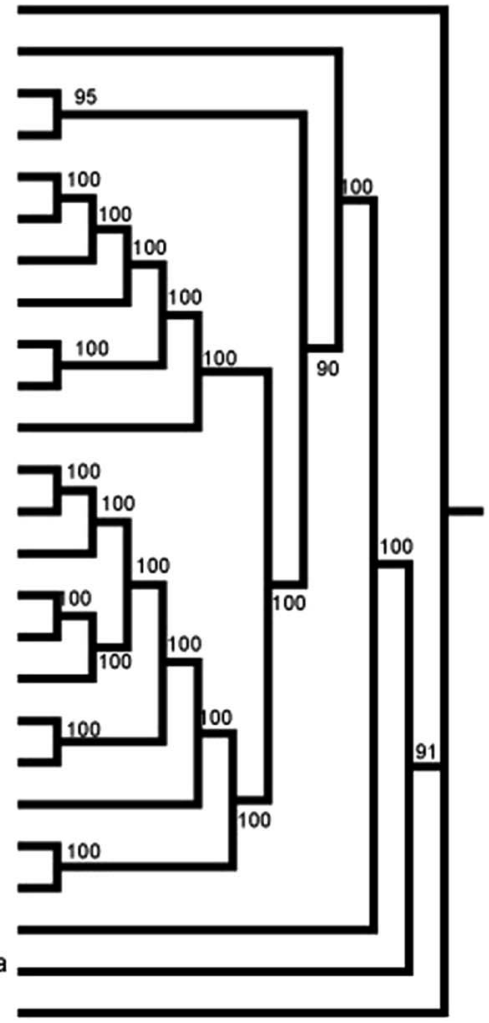

Fig. 10 Results of phylogenetic analysis using hagfish backbone constraint. Analysis using updated characters for euconodonts (true conodonts) places conodonts as basal cyclostomes. (A) Strict consensus and (B) majority rule consensus of 115 most parsimonious trees (MPTs; 206 steps, C.I. $=0.597$, R.I. $=0.677)$. Numbers in (A) represent Bremer support, and in (B) frequency this node was found in all MPTs.

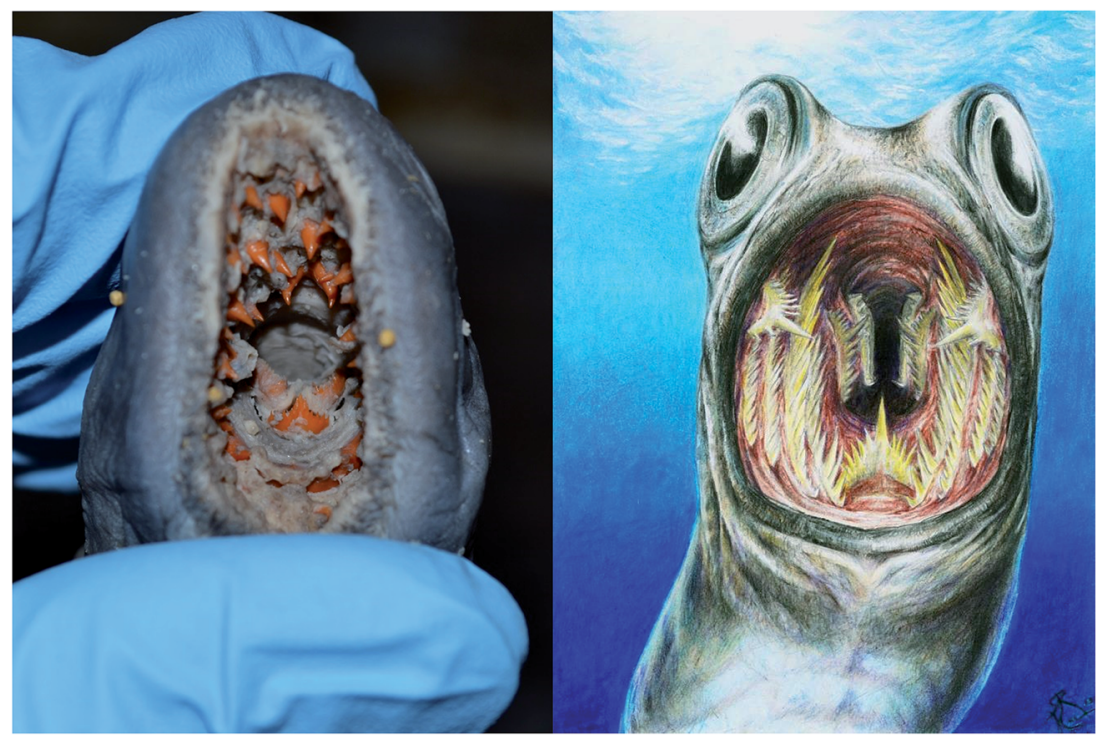

Fig. 11 Comparison of oral morphology between modern lampreys and conodonts. Both the lamprey (left) and conodont animal (right, artistic interpretation from Sydney Mohr) have jawless oral cavities containing a central symmetrical denticulate element, broader lingual elements near the back of the oral cavity, and an array of elements located in the anterior of the oral cavity. The main differentiating factor is composition, with lamprey (Petromyzontida) elements being almost entirely keratinous, while conodont elements are primarily phosphatic in composition. 
The overall preservation of keratin itself as a fossil tissue remains a topic of debate. Recent work by Moyer $e t a l .^{46}$ suggest that keratin has a high preservation potential, with signals separating alpha and beta keratin being detectable in the fossil record. In contrast, work done by Saitta et al. ${ }^{47}$ indicate that keratin has a very low fossilization potential and would likely be leached from fossils during diagenesis, leaving only calcium phosphate and pigments. Here it is suggested that degraded keratin was not leached from the conodonts, presumably because phosphatic lamellae were not porous, but rather was preserved as a carbon and sulfur residue.

\section{Phylogenetic analysis}

Utilizing the observations of sulfur preservation within conodont fossils, it is suggested that conodont oral elements were not completely phosphatic, but may have contained a keratinous intralamellar structure concentrated in the juvenile stages of growth and possibly in the basal body of the element. While most of the elements we examined are Permian in age, we also examined a chirognathid specimen from the Ordovician Harding Sandstone Formation (Fig. 9C). While the specimen we examined had very little visible intralamellar tissue, there was still a significant concentration of sulfur in the basal body with slight traces along the growth axis. This suggests that the proposed keratinous framework is likely not a derived feature of more advanced conodonts, but is in fact a primitive condition. With the established homology between the basal body of conodonts and the elements of paraconodonts, ${ }^{10}$ it may be possible to trace the presence of keratin back to the Cambrian.

These observations have been incorporated into a phylogenetic analysis from Caron and Conway-Morris ${ }^{5}$ to see if conodont affinities within the vertebrate clade are affected (full character details are included in the ESI $\dagger$ ). In addition, a number of characters for conodonts based on well-known traits and new research were corrected. These include characters involving the composition of the oral elements, functionality of the conodont apparatus, and the presence of eyes. A detailed breakdown of characters can be found in the ESI. $\dagger$ Due to the unusual case of hagfish, whose genetics support monophyly (direct evolutionary relationship) with lampreys as part of Cyclostomata despite significant morphologic differences, two analyses were performed; one with a cyclostome monophyly constraint (per Conway-Morris and Caron ${ }^{5}$ ) and one without. Aside from the position of hagfishes, the results of these analyses are identical. Conodonts in both cases are determined as a sister-group to lampreys, with the implication that they are stem cyclostomes, if we assume cyclostome monophyly (Fig. 10, ESI†).

\section{Biological affinity of conodonts}

Because of strong morphologic similarities between conodonts and lampreys, coupled with the results of the phylogenetic analysis, it was decided to apply the same suite of analytical techniques to a lamprey oral element as in the conodont elements. The results are mostly unsurprising, however, one unexpected outcome was the observation of trace amounts of calcium and phosphorous along the inner surface of the lamprey element. This is surprising as lampreys are not believed to have the ability to mineralize tissue, although some work has

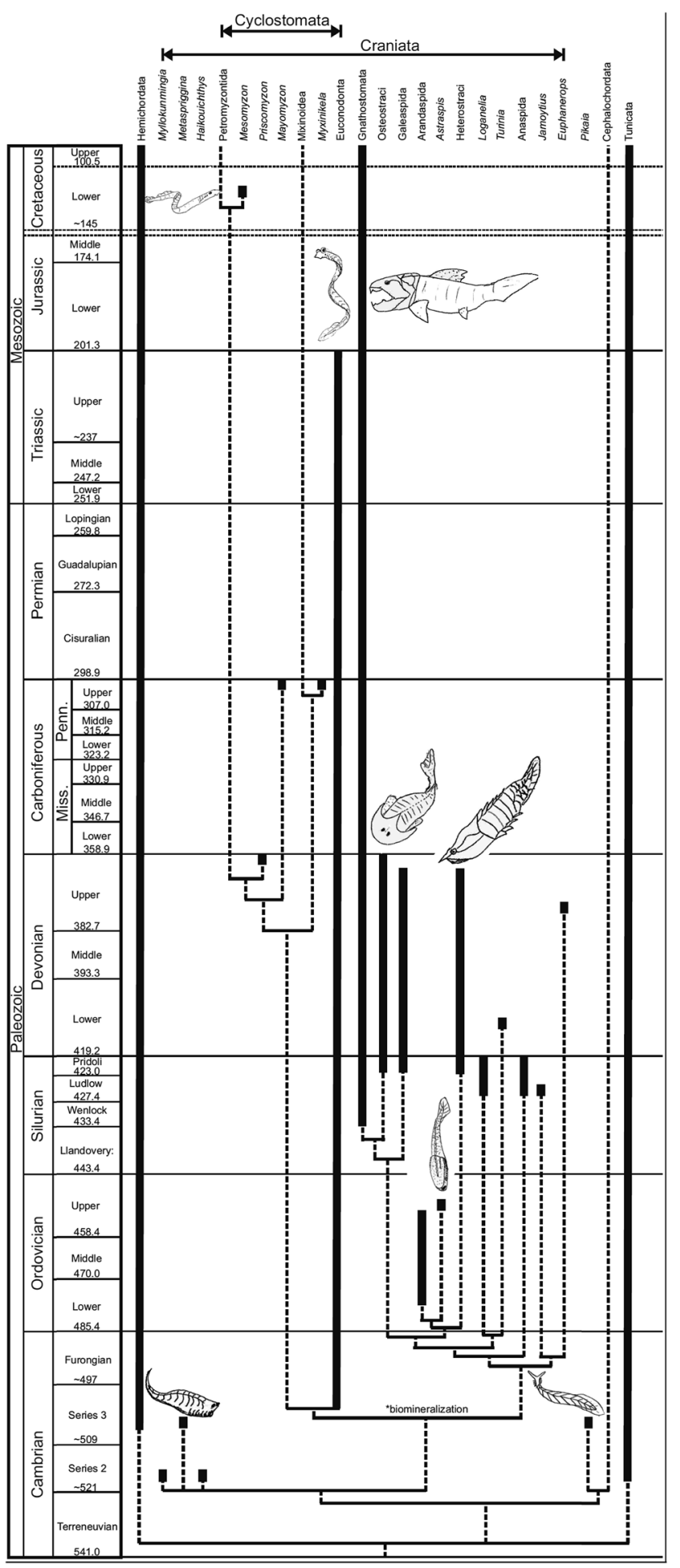

Fig. 12 Vertebrate phylogeny showing temporal relationships between taxa. This diagram is informed by the phylogenetic analysis depicted in Fig. 10. Of note is the relative absence of cyclostome fossils in comparison to the fossil record of conodonts. Dashed lines link determined relationships, while wider solid lines represent the occurrence of each group in the rock record. 
been able to produce in vitro calcification in lamprey cartilage, ${ }^{48}$ and vitamin D receptors have also been successfully cloned from lamprey tissue. ${ }^{49}$ While lamprey biomineralization is restricted,$^{\mathbf{4 8}}$ it is possible that lampreys may have at some point in their evolutionary history had the ability to mineralize tissue in a way similar to conodonts and other vertebrates.

This is not the first time conodonts have been suggested to have cyclostome affinities. ${ }^{\mathbf{3 0 , 5 0 , 5 1}}$ Although the vertebrate diagnosis of conodonts is based largely on soft tissue evidence, such as the presence of a notochord, myomeres, and ray supported fins, ${ }^{7,15,16}$ the cyclostome diagnosis was first suggested by Kresja $^{30}$ owing to similarities in size and morphology of the oral apparatus. ${ }^{30}$ Kresja suggested that the size and shape of hagfish dental plates were morphologically similar to conodont oral elements, and suggested that the basal body of conodont elements were representative of replacement teeth, a feature found in both lamprey and hagfish oral elements. ${ }^{30}$ This has been shown not to be the case, with further work concluding that conodonts were more likely to be gnathostomes than cyclostomes. ${ }^{19}$

Despite flaws in Kresja's argument, the similarity in morphology between conodont elements and cyclostome dental plates is difficult to ignore. This is especially true of lamprey lingual tooth plates, which comprise a number of morphologically distinct elements within a bilaterally symmetrical apparatus resembling that of the conodont apparatus (Fig. 11). More recently it has been shown that the function of the conodont oral apparatus is homologous with the lingual apparatus of lampreys, ${ }^{51}$ further suggesting a close relationship between the two groups.

The apatitic composition and method of growth of conodont elements have remained as stumbling blocks to the placement of conodonts within the Cyclostomata, ${ }^{18,51}$ as modern cyclostome oral elements are purely keratinous. It has been suggested that conodont elements may have been covered by a horny outer layer as in modern cyclostomes, but such a layer remains hypothetical. ${ }^{52}$ Assuming the presence of internal keratin as suggested in this study by the presence of biologic sulfur, it is possible to eliminate the barrier of composition. This is further supported by the above identified possibility of ancestral mineralization of lamprey elements.

\section{Conclusion}

The identification of biologic sulfur associated with carbon within conodont elements suggests the concentrated presence of degraded keratinous residue within the fossil. This would be the oldest recorded observation of degraded keratin in the fossil record, and may be the only evidence of degraded keratin preservation from the Paleozoic; other finds are limited to Mesozoic land vertebrates. ${ }^{\mathbf{1} 25-27}$ If correct, the recognition of keratinous residue is significant and has major ramifications for early vertebrate phylogeny.

The conodont fossil record is quite robust throughout most of the Paleozoic and Triassic, which is in stark contrast to the fossil record of modern cyclostomes. Molecular evidence suggests cyclostomes diverged from jawed vertebrates (or gnathostomes) early in the Paleozoic or even the Neoproterozoic, ${ }^{53}$ but the earliest known fossil of a cyclostome occurs over 150 million years later during the Devonian period. ${ }^{31}$ Although the body plan of cyclostomes is thought to be quite conservative and in many respects representative of early vertebrate forms ${ }^{18}$ it is still remarkable that by the time cyclostomes appear in the fossil record their morphology is already mostly consistent with that seen in modern lamprey species. ${ }^{31}$ This lack of fossil evidence of more primitive morphology makes cyclostome evolution difficult to infer; ${ }^{18}$ however, if the Conodonta are stem cyclostomes, it would significantly fill in the gaps of the cyclostome fossil record (Fig. 12). Additionally, the ability of conodonts to biomineralize, combined with the possibility lamprey ancestors produced some mineralized tissue, suggests that biomineralization may in fact be a primitive condition of all Cyclostomata. Given the abundance of mineralized tissues within Gnathostomata, the ability to synthesize calcium phosphate may be a homologous feature of all vertebrates. The detection of biomarkers for soft tissues is increasing with the wider availabilities of technologies such as EDX and XPS, and is providing new avenues through which to study the fossil record.

As shown in this study, a small observation of soft tissue preservation can have large effects on understanding of the biology and evolutionary history of ancient life. Further studies on early conodonts and paraconodonts should be pursued to confirm the conclusion of conodont monophyly within the Cyclostomata, and it is recommended that these methods be used to further understand soft tissue of other vertebrate fossil groups.

\section{Funding}

This study was funded by a Natural Sciences and Engineering Research Council of Canada (NSERC) Discovery Grant held by CMH (RT730228/RGPIN04122-2017).

\section{Conflicts of interest}

The authors state no competing interests.

\section{Acknowledgements}

We would like to acknowledge the hard work of the people and technicians who assisted in the collection of data used in this study, in particular Mickey Horvath for assistance in sample mounting and design, as well as Chris Debuhr for assistance with the FE-SEM, and Maria Josefina Perez-Zurita for assistance with the XPS equipment and analysis. Finally, we would also like to acknowledge the work of Sydney Mohr, the artist who produced the interpretative drawing of the conodont in Fig. 10.

\section{References}

1 P. Chen, Z. Dong and S. Zhen, Nature, 1998, 398, 147-152.

2 N. Butterfield, Paleobiology, 1990, 16, 272-286. 
3 R. R. Gaines, D. E. G. Briggs and Z. Yuanlong, Geology, 2008, 36, 755-758.

4 P. A. Allison and D. E. G. Briggs, Geology, 1993, 21, 527-530.

5 S. Conway-Morris and J. B. Caron, Nature, 2014, 512, 419422.

6 S. Conway-Morris and J. B. Caron, Biol. Rev., 2012, 87, 480512.

7 D. E. G. Briggs, E. N. K. Clarkson and R. J. Aldridge, Lethaia, 1983, 16, 1-14.

8 C. H. Pander, Monagraphie der fossilen Fische des silurischen Systems der russich-baltischen Gouvernements, Kaiserlichen Akademie der Wissenschaften, 1856, p. 91.

9 S. Bengston, Lethaia, 1976, 9, 185-206.

10 D. J. E. Murdock, X. P. Dong, J. E. Repetski, F. Marone, M. Stamponi and P. C. J. Donoghue, Nature, 2013, 502, 546-549.

11 P. C. J. Donoghue and M. A. Purnell, Geology, 1999, 27, 251-254. 12 M. A. Purnell and D. Jones, Paleobiology, 2012, 38, 605-626. 13 M. A. Purnell, Nature, 1995, 374, 798-800.

14 I. J. Sansom, M. P. Smith, H. A. Armstrong and M. M. Smith, Science, 1992, 256, 1308-1311.

15 S. E. Gabbott, R. J. Aldridge and J. N. Theron, Nature, 1994, 374, 800-803.

16 R. J. Aldridge, D. E. G. Briggs, M. P. Smith, E. N. K. Clarkson and N. D. L. Clark, Philos. Trans. R. Soc., B, 1993, 340, 405-421.

17 M. A. Purnell, R. J. Aldridge, P. C. J. Donoghue and S. E. Gabbott, Endeavour, 1995, 19, 20-27.

18 P. Janvier, Early jawless vertebrates and cyclostomes origins, Zool. Sci., 2008, 25, 1045-1056.

19 P. C. J. Donoghue, P. L. Forey and R. J. Aldridge, Biol. Rev. Cambridge Philos. Soc., 2000, 75, 191-251.

20 R. L. Denham, J. Paleontol., 1944, 18, 216-218.

21 A. Kemp, Proc. Linn. Soc. N. S. W., 1984, 107, 245-262.

22 A. Blieck, S. Turner, C. J. Burrow, H. Schultze, C. B. Rexroad, P. Bultynck and G. S. Nowlan, Episodes, 2010, 33, 234-241.

23 S. Turner, C. J. Burrow, H. Schultze, A. Blieck, W. Reif, C. B. Rexroad, P. Bultynck and G. S. Nowlan, Geodiversitas, 2010, 32, 545-594.

24 E. C. Katvala and C. M. Henderson, Paleobiology, 2012, 38, 447-458.

25 U. Bergmann, R. W. Morton, P. L. Manning, W. I. Sellers, S. Farrar, K. G. Huntley, R. A. Wogelius and P. Larson, Proc. Natl. Acad. Sci. U. S. A., 2010, 107, 9060-9065.

26 V. M. Egerton, R. A. Wogelius, M. A. Norell, N. P. Edwards, W. I. Sellers, U. Bergmann, D. Sokaras, R. Alonso-Mori, K. Ignatyev, A. van Veelen, J. Anné, B. van Dongen, F. Knoll and P. L. Manning, J. Anal. At. Spectrom., 2015, 30, 627-634.

27 P. L. Manning, N. P. Edwards, R. A. Wogelius, U. Bergmann, H. E. Barden, P. L. Larson, D. Schwartz-Wings, V. M. Egerton, D. Sokaras, R. A. Mori and W. I. Sellers, J. Anal. At. Spectrom., 2013, 28, 1024-1030.

28 M. H. Schweitzer, J. A. Watt, R. Avci, C. A. Forster, D. W. Krause, L. Knapp, R. R. Rogers, I. Beech and M. Marshall, J. Vertebr. Paleontol., 1999, 19, 712-722.
29 Y. Pan, W. Zheng, A. E. Moyer, J. K. O'Connor, M. Wang, X. Zheng, X. Wang, E. R. Schoeter, Z. Zhou and M. H. Schweitzer, Proc. Natl. Acad. Sci. U. S. A., 2016, 113, E7900-E7907.

30 R. J. Krejsa, P. Bringas Jr and H. C. Slavkin, Lethaia, 1990, 23, 359-378.

31 R. W. Gess, M. I. Coates and B. S. Rubidge, Nature, 2006, 443, 981-984.

32 M. Chang, F. Wu, D. Miao and J. Zhang, Proc. Natl. Acad. Sci. U.S.A., 2014, 111, 15486-15490.

33 L. Kövér, Surf. Interface Anal., 2006, 38, 1173-1175.

34 D. A. Shirley, Phys. Rev. B: Solid State, 1972, 5, 4709-4717.

35 ISO 15472:2001 - Surface Chemical Analysis - X-ray Photoelectron spectrometers - Calibration of Energy Scale.

36 J. H. Scofield, J. Electron Spectrosc. Relat. Phenom., 1976, 8, 129-141.

37 Surface Analysis by Auger and X-ray Photoelectron Spectroscopy, ed. M. P. Seah, D. Briggs and J. T. Grant, IM Publication Surface Science Spectra Limited, 2003, pp. 354-375.

38 P. C. J. Donoghue, Philos. Trans. R. Soc., B, 1998, 353, 633666.

39 J. Dzik, Evol. Dev., 2008, 10, 769-777.

40 H. A. Armstrong and C. J. Smith, Proc. R. Soc. B, 2001, 268, 815-820.

41 M. H. Schweitzer, R. Avci, T. Collier and M. B. Goodwin, Comptes Rendus Palevol, 2008, 7, 159-184.

42 C. M. Carr, I. H. Leaver and A. E. Hughes, Text. Res. J., 1986, 56, 457-461.

43 L. Alibardi and A. Segalla, Zool. Stud., 2011, 50, 416-425.

44 J. T. Brosnan and M. E. Brosnan, J. Nutr., 2006, 136, 16361640.

45 A. Giroud and C. P. Leblond, Ann. N. Y. Acad. Sci., 1951, 53, 613-626.

46 A. E. Moyer, W. Zheng and M. H. Schweitzer, PLoS One, 2016, 11.

47 E. T. Saitta, C. Rogers, R. A. Brooker, G. D. Abbott, S. Kumar, S. S. O'Reilly, P. Donoghue, S. Dutta and R. E. Summons, Paleontology, 2017, 60, 547-556.

48 R. M. Langille and B. K. Hall, Acta Zool., 1993, 74, 31-41.

49 G. K. Whitfield, H. T. L. Dang, S. F. Schluter, R. M. Bernstein, T. Bunag, L. A. Manzon, G. Hsieh, C. E. Dominguez, J. H. Youson, M. R. Haussler and J. J. Marchalonis, Endocrinology, 2003, 144, 2704-2716.

50 R. S. Sansom, K. Freedman, S. E. Gabbott, R. J. Aldridge and M. A. Purnell, Palaeontology, 2010, 53, 1393-1409.

51 N. Goudemand, M. J. Orchard, S. Urdy, H. Bucher and P. Tafforeau, Proc. Natl. Acad. Sci. U. S. A., 2011, 108, 87208724.

52 J. Dzik, Evol. Biol., 2000, 31, 105-154.

53 S. B. Blair, in Major events in Early Vertebrate Evolution: Palaeontology, Phylogeny, Genetics and Development, ed. P. E. Ahlberg, Taylor and Francis, London and New York, 2001, pp. 119-134. 